\title{
The great Indian haze revisited: aerosol distribution effects on microphysical and optical properties of warm clouds over peninsular India
}

\author{
R. Ghanti ${ }^{1}$ and S. Ghosh ${ }^{1,2}$ \\ ${ }^{1}$ School of Mechanical and Building Sciences, Vellore Institute of Technology, Vellore, India \\ ${ }^{2}$ School of Earth and Environment, University of Leeds, Leeds, UK
}

Received: 5 September 2009 - Revised: 26 February 2010 - Accepted: 26 February 2010 - Published: 10 March 2010

\begin{abstract}
The Indian subcontinent is undergoing a phase of rapid urbanisation. Inevitable fallout of this process is a concomitant increase in air pollution much of which can be attributed to the infamous great Indian haze phenomena. One observes that the aerosol size distributions vary considerably along the Bay of Bengal (BOB), Arabian Sea (AS) and the Indian Ocean (IO), although, the dynamical attributes are very similar, particularly over the BOB and the AS during this season. Unlike major European studies (e.g. Aerosol Characterization Experiment-2, Ghosh et al., 2005), there are no cloud microphysical modelling studies to complement these observational results for the Indian sub-continent. Ours is the first modelling study over this important region where a time-tested model (O'Dowd et al., 1999a; Ghosh et al., 2007; Rap et al., 2009) is used to obtain cloud microphysical and optical properties from observed aerosol size distributions. Un-activated aerosol particles and very small cloud droplets have to be treated specially to account for non-ideal effects-our model does this effectively yielding realistic estimate of cloud droplet number concentrations $(\mathrm{Nc})$. Empirical relationships linking aerosol concentration to $(\mathrm{Nc})$ yield a disproportionately higher Nc suggesting that such empirical formulations should be used with caution. Our modelling study reveals that the cloud's microphysical and optical properties are very similar along the AS and the BOB despite them having disparate dry aerosol spectral distributions. This is non-intuitive, as one would expect changes in microphysical development with widely different aerosol distributions. There is some increase in cloud droplet numbers with increased haze concentrations but much less than a simple proportion would indicate.
\end{abstract}

Correspondence to: S. Ghosh

(satyajitg@vit.ac.in)

\section{Introduction}

Prior to the summer monsoon, from December to April every year, trade wind blowing from the northeast brings polluted continental air over the Arabian Sea and also parts of the Bay of Bengal. Since the wind blows over much of continental India covering many mega-cities (Mumbai, Kolkata, Chennai), the aerosol concentrations are high. This is in contrast to the Indian Ocean case - here the largest sulphate mode concentration is lower than $10^{4}$ particles $/ \mathrm{cm}^{3}$ indicating comparatively pristine conditions shown in Fig. 1b. Air masses from both the coastline, as well as from the Indo - Gangetic plains, are expected to converge over the Indian Ocean leading to a wider spread of the particle size distribution of the sulphate mode. This latter feature essentially indicates that the spectrum comprises of a variety of aerosol particles with differing origins. The cloud nucleating potential of aerosol mixtures has been little studied over this part of the world. In this study, we first endeavor to establish how effectively can cloud droplets grow from observed distributions of aerosol particles, secondly, if they at all grow into full-fledged cloud droplets, are there significant differences in the cloud microphysical and optical properties over the 3 regions? To our knowledge this is the first study of its kind over this part of the world.

\section{Cloud microphysical development}

A detailed microphysical chemical parcel model was the main tool used (O'Dowd et al., 1999a; Ghosh et al., 2007). The chemical model used is, in essence, a Lagrangian parcel model with explicit microphysics using the dynamic growth equation (Pruppacher and Klett, 1997) to model the growth of aerosol solution droplets by condensation of water vapour onto a size-resolved droplet spectrum. As indicated earlier,

Published by Copernicus Publications on behalf of the European Geosciences Union. 


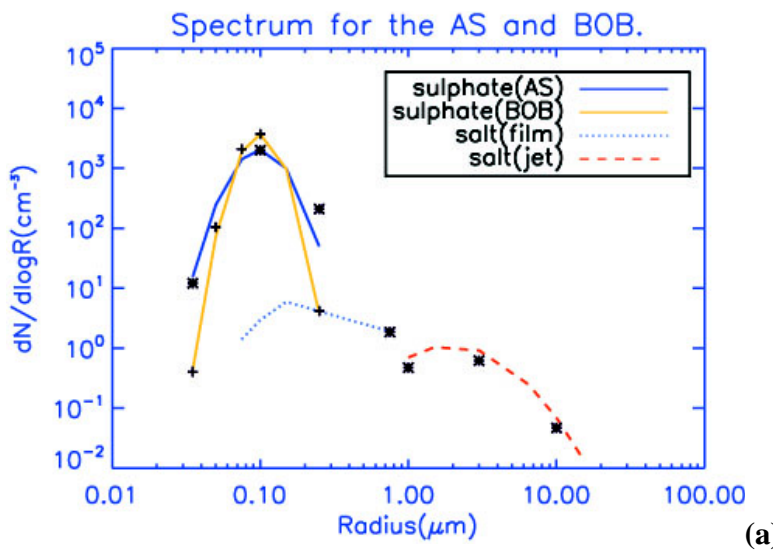

(a)

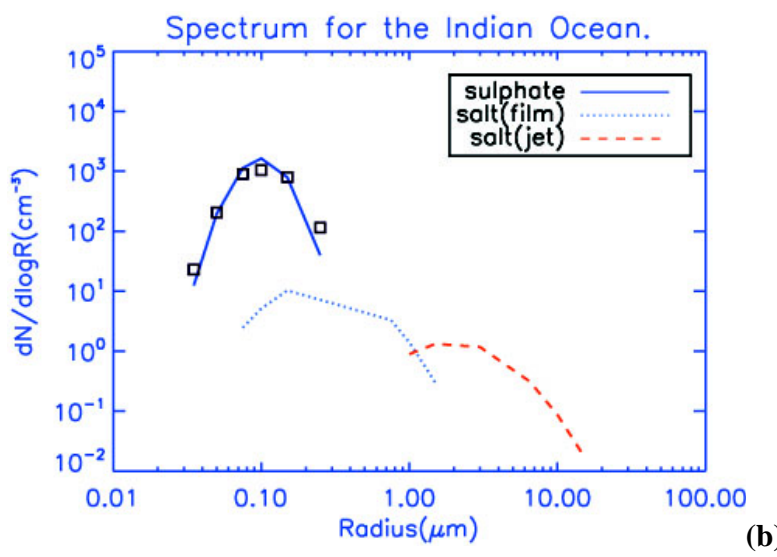

(b)

Fig. 1. Dry aerosol spectra for (a) AS and BOB (* and + represents the data observed by Jayaraman (2001) and Murugavel et al. (2008) respectively) and (b) Indian Ocean (represents the data observed by Murugavel et al., 2001). There were no observational data points for salt distributions for BOB and IO-wind-speed dependent estimates are shown.

the main strength of this modelling study lies in accurate estimates of growth rates of aerosol particles under non-ideal conditions which one frequently encounters for the smallest of the aerosol particles shown in Fig. 1. The fine mode spectra were assumed to comprise of mainly ammonium sulphate with some contribution of film-mode sea salt particles. The coarse jet mode particles on the other hand were assumed to be sea salt particles only.

We used the wind speed dependant model suggested by O'Dowd et al. (1999b) to generate the fine and coarse mode sea salt number concentrations. We used observed values of wind speeds (Satheesh et al., 2001) i.e. in the range 5$8 \mathrm{~ms}^{-1}$ and standard distribution spreads (Ghosh et al., 2007; Jones et al., 1999) used in global climate models (Table 1) to create log-normally distributed dry aerosol spectra shown in Fig. 1a-b.

Partial pressures of all gaseous species were based on conservative estimates based on long-term global average values $\left(\mathrm{CO}_{2}-350 \mathrm{ppm}, \mathrm{NH}_{3}-0.3 \mathrm{ppb}, \mathrm{O}_{3}-30 \mathrm{ppb}, \mathrm{H}_{2} \mathrm{O}_{2}-1 \mathrm{ppb}\right.$,
$\mathrm{SO}_{2}-5 \mathrm{ppt}, \mathrm{HCl}-10^{-5} \mathrm{ppt}$ ) used by the UKMO (Ghosh et al., 2007). These gas phase concentrations are fairly typical over these regions-on specific days however, variations are observed.

The temperature, pressure, relative humidity, updraught speed $(U)$ and ammonium to sulphate molar ratio of the parcel were also supplied as input in the first model time step and represent typical conditions for this season; they are $15.0^{\circ} \mathrm{C}$, $843.0 \mathrm{hPa}, 98.9 \%, 0.4 \mathrm{~ms}^{-1}$ and 0.8 respectively. The above input data are kept identical in order to specifically single out the impact of the aerosol distribution pattern on the cloud microphysical and optical development along the coast of peninsular India. Observations reveal that representative values of cloud base height and the vertical updraught speed were respectively $843 \mathrm{hPa}$ and $0.4 \mathrm{~ms}^{-1}$ and did not vary between polluted (representative of the BOB and the AS) and pristine clouds (representative of the IO) (Ramanathan et al., 2001). This study primarily focuses on a specific period over which the preponderance of haze particles is particularly noticed-a season with rather low to moderate updraught speeds which do not show significant coast-to-coast variability.

We find that the level of maximum super saturation for the Arabian Sea, Bay of Bengal and Indian Ocean are respectively $0.044 \%, 0.046 \%$ and $0.046 \%$ at heights $77 \mathrm{~m}, 81 \mathrm{~m}$ and $77 \mathrm{~m}$ above the cloud base.

\section{Spectral development at cloud top for sulphate and coarse mode particles}

From Fig. 2, we find that the fine mode spectrum at cloud top for $\mathrm{BOB}$ shows the highest number densities. Although the AS number concentrations are in between the BOB (highly polluted in terms of aerosol number concentrations) and IO (least polluted) cases, the spectral shapes of the cloud droplet distributions are similar for AS and IO.

The spectral distributions for AS and $\mathrm{BOB}$ for the coarse mode salt based droplets are identical - this indicates that very large coarse mode particles easily activate - their growth is mainly controlled by the updraught speed which are similar for all the 3 cases. Over the IO however, larger horizontal wind speeds were observed (Satheesh et al., 2001), hence the higher number densities.

There is a greater domination of finer particles over the Bay of Bengal; the number of particles belonging to the 0.5$2 \mu \mathrm{m}$ radius regime are 5575 particles $/ \mathrm{cm}^{3}$; this is more than over the Arabian Sea which has 3660 particles $/ \mathrm{cm}^{3}$ and the Indian Ocean with 2928 particles $/ \mathrm{cm}^{3}$. In Fig. 3, we have shown typical growth profiles for the fine mode salt particleswe observe that the particles start to grow, but after an initial growth, they shrink back to smaller sizes. Similar trends are observed for the smallest sulphate based droplets also. This implies that, owing to their smaller sizes, these particles fail to activate and remain as haze contributing to the aerosol 
Table 1. Input aerosol spectral properties for the three regions.

\begin{tabular}{lcccccccc}
\hline $\begin{array}{l}\text { Aerosol } \\
\text { Type }\end{array}$ & $\begin{array}{c}\text { Mean }(\mathrm{nm}) \\
\text { radius }\end{array}$ & \multicolumn{2}{c}{ s.d. $(\sigma)$} & & $\begin{array}{c}\text { Density } \\
\left(\mathrm{kg} / \mathrm{m}^{3}\right)\end{array}$ & $\begin{array}{c}\text { Integrated No. Concentration, } \mathrm{N}_{a} \\
\left(\mathrm{~cm}^{-3}\right)\end{array}$ & AS \\
& & BOB & IO & & AS & BOB & IO \\
\hline Ammonium sulphate & 100 & 1.4 & 1.28 & 1.4 & 1769 & 4770 & 6650 & 3816 \\
Sea salt (film mode) & 250 & 1.9 & 1.9 & 1.9 & 2165 & 10.75 & 10.75 & 18.73 \\
Sea salt (jet mode) & 1950 & 2.0 & 2.0 & 2.0 & 2165 & 2.65 & 2.65 & 3.38 \\
\hline
\end{tabular}

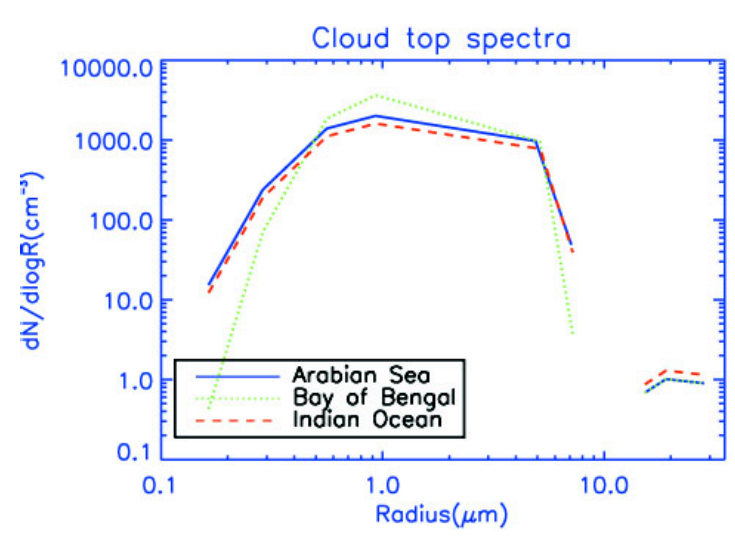

Fig. 2. Spectra at the cloud top for sulphate and salt based droplets for the three regions.

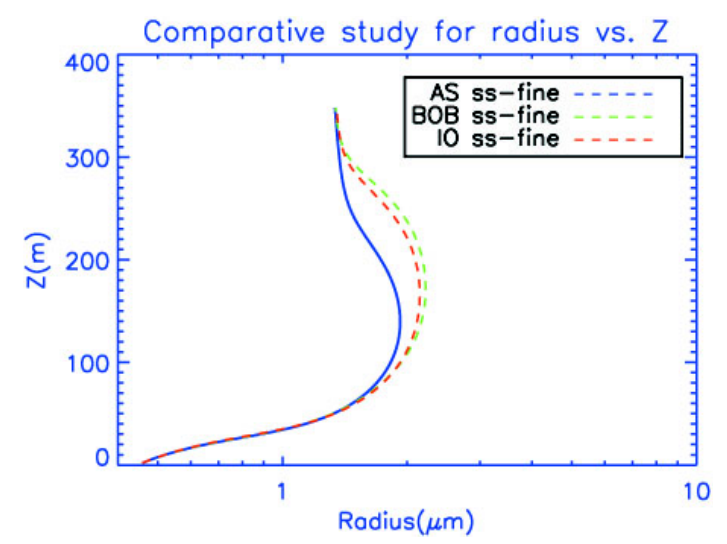

Fig. 3. Growth profile of the smallest fine mode salt particles.

direct effect rather than aerosol indirect effect. These concentrated haze droplets exhibit non-ideal effects where the water activity is less than one.

\section{Optical properties}

Cloud optical depth $(\tau)$ is relatively independent of wavelength throughout the visible spectrum. A general way of estimating the cloud optical depth $\tau$ is given by $\tau=\frac{3}{2} \int \frac{q_{l}(z) d z}{\rho_{w} r_{e}(z)}$

$\rho_{w}$ and $\mathrm{q}_{l}$ are the liquid water density and the liquid water content (LWC), respectively, and the integration extends from the cloud base to the cloud top. $r_{e}$ is the droplet effective radius, which is the ratio of the third to the second moment of the size spectrum. $q_{l}$ and $\mathrm{N}_{c}$ (cloud droplet number concentration) are obtained from the model outputs. The maximum values of the effective radii are close to the cloud top while the minimum values are towards the cloud base. Only limited observational data are available for the Indian sub-continent. When available, the cloud droplet number concentrations are inferred from empirical results linking cloud condensation nuclei to aerosol number concentrations as suggested by Ramanathan et al. (2001) (see their equations $\mathrm{A} 2$ and $\mathrm{A} 4)$.

We now discuss the observed cloud optical properties. Modelled values of the cloud droplet number concentration, effective radii and the optical depths are shown in Table 2 below. The LWC is close to $0.36 \mathrm{~g} / \mathrm{kg}$ for all the three cases. Large values of optical depths are observed for the AS and the $\mathrm{BOB}$ as compared to the Indian Ocean; this is to be expected as the IO represents relatively pristine conditions. However, the most interesting observation is that the effective radii and optical depths over the BOB and the AS are very similar; although the dry aerosol size distributions (see Fig. 1a-b) are very different. Observed values of the optical depths and effective radii for this season are only available for Indian Ocean (Ramanathan et al., 2001) and we find that our modelled values agree well with the observed values shown within brackets in the 3rd and 4th columns of Table 2 . If one were to use empirical relations, one would observe very different values of the cloud droplet number concentrations (as seen in the 5th column of Table 2). This study illustrates that when counting cloud droplet number concentrations grown from very small aerosol particles one should use sophisticated models to grow aerosol particles into cloud droplets (Ghanti and Ghosh, 2009); not all aerosol particles are able to overcome the Kohler Barrier. Only favoured particles with the right size surrounded by the right amount of vapour super saturation get activated into cloud droplets. This exercise suggests that the great Indian haze may well induce differing aerosol distributions, but the resultant cloud 
Table 2. Modelled optical properties over the three regions.

\begin{tabular}{lcccc}
\hline Region & $\begin{array}{c}\text { Mean Cloud and Haze } \\
\text { Droplet No. Conc. }\left(\mathrm{cm}^{-3}\right)^{*}\end{array}$ & $\begin{array}{c}\text { Effective Diameter } \\
(\mu \mathrm{m})^{*}\end{array}$ & $\begin{array}{c}\text { Cloud Optical } \\
\text { Depth }(\tau)^{*}\end{array}$ & $\begin{array}{c}\text { Empirically deduced } \\
\mathrm{N}_{c}\left(\mathrm{~cm}^{-3}\right)\end{array}$ \\
\hline Arabian Sea & $342(3660)$ & $2.98-10.54$ & 34.03 & 992.8 \\
Bay of Bengal & $319(5575)$ & $3.11-10.8$ & 33.26 & 1554.4 \\
Indian Ocean & $119(2928)$ & $5.21-17.16(10-16)$ & $21.15(\sim 16)$ & 780 \\
\hline
\end{tabular}

* The bracketed quantities in column 2 refer to the haze number concentrations.

The bracketed quantities in column 3 and 4 refer to observed values.

microphysical and optical properties are by and large similar along the two coasts. The reason for this is as follows: the spectral distributions have widely different number concentrations over the AS and BOB, but these variations occur over the finest sizes. For similar updraught speeds and relative humidity levels, the actual cloud droplet number concentrations (i.e. essentially those favoured hydrated droplets that are able to overcome the Kohler barrier) are not very different (controlled mainly by the updraught speed). The cloud droplet number concentration Nc shows some sensitivity with updraught speeds. Sensitivity studies using the same model (Ghosh et al., 2007) with polluted air masses reveal that when updraught speed increased from 0.2 to $0.5 \mathrm{~ms}^{-1}$, corresponding to the range valid for the present analysis, $\mathrm{N}_{c}$ increased by approximately $10 \%$. The large differences in the number concentrations of the dry aerosol particles (mainly the sulphate aerosol particles and the film mode salt particles) are manifest in the number concentration of the haze number concentrations (i.e. those hydrated droplets that have radii less than 0.5 micron radius).

Acknowledgements. The authors wish to thank the Director of SMBS, VITU for his continuing support.

Edited by: S. C. Michaelides

Reviewed by: two anonymous referees

\section{References}

Ghanti, R. and Ghosh, S.: Contrasting aerosol and cloud microphysical processes along the Arabian Sea, Bay of Bengal and the Indian Ocean, EGU General Assembly 2009, Vienna, Austria, 19-24 April 2009, Vol. 11, 2009.

Ghosh, S, Smith, M. H., and Rap, A.: Integrating biomass, sulphate and sea-salt aerosol responses into a microphysical chemical parcel model: implications for climate studies, Phil. Trans. Roy. Soc. A., 365, 2659-2674, 2007.

Ghosh, S., Osborne, S., and Smith, M. H.: On the importance of cumulus penetration on the microphysical and optical properties of stratocumulus clouds, Atmos. Chem. Phys., 5, 755-765, 2005, http://www.atmos-chem-phys.net/5/755/2005/.

Jayaraman, A.: Aerosol radiation cloud interactions over the tropical Indian Ocean prior to the onset of the summer monsoon, Curr. Sci. India, 81, 1437-1445, 2001.
Jones, P. D., New, M., Parker, D. E., Martin, S., and Rigor, I. G.: Surface air temperature and its variations over the last 150 years, Rev. Geophys., 37, 173-199, 1999.

Murugavel, P., Pawar, S. D., and Kamra, A. K.: Size-distribution of submicron aerosol particles over the Indian Ocean during IFP-99 of INDOEX, Curr. Sci. India, 80, 123-127, 2001.

Murugavel, P., Gopalakrishnan, V., Pant, V., and Kamra, A. K.: Airborne measurements of submicron aerosols acrossthe coastline at Bhubaneswar during ICARB, J. Earth Syst. Sci., 117, 273-280, 2008.

O’Dowd, C., Lowe, J. A., and Smith, M. H.: Observations and modelling of aerosol growth in marine stratocumulus - case study, Atmos. Environ., 33, 3053-3062, doi:10.1016/S135223109800213-1, 1999a.

O'Dowd, C., Lowe, J. A., and Smith, M. H.: Coupling seasalt and sulphate interactions and its impact on cloud droplet concentration predictions, Geophys. Res. Lett., 26, 1311-1314, doi:10.1029/1999GL900231, 1999b.

Pruppacher, H. R. and Klett, J. D.: Microphysics of clouds and precipitation, Kluwer Academic Publishers, Dordredcht, The Netherlands, 1997.

Ramanathan, V., Crutzen, P. J., Lelieveld, J., Mitra, A. P., Althausen, D., Anderson, J., Andreae, M. O., Cantrell, W., Cass, G. R, Chung, C. E., Clarke, A. D., Coakley, J. A., Collins, W. D., Conant, W. C., Dulac, F., Heintzenberg, J., Heymsfield, A. J., Holben, B., Howell, S., Hudson, J., Jayaraman, A., Kiehl, J. T., Krishnamurti, T. N., Lubin, D., McFarquhar, G., Novakov, T., Ogren, J. A., Podgorny, I. A., Prather, K., Priestley, K., Prospero, J. M., Quinn, P. K., Rajeev, K., Rasch, P., Rupert, S., Sadourny, R., Satheesh, S. K., Shaw, G. E., Sheridan, P., and Valero, F. P. J.: Indian Ocean Experiment: An integrated analysis of the climate forcing and effects of the great Indo-Asian haze, J. Geophys. Res., 106, 28371-28398, 2001.

Rap, A., Ghosh, S., and Smith, M. H.: Shepard and Hardy Multiquadric Interpolation Methods for Multicompon Aerosol-Cloud Parameterization, J. Atmos. Sci., 66, 105-115, doi:10.1175/2008JAS2626.1, 2009.

Satheesh, S. K., Krishna Moorthy, K., and Das, I.: Aerosol spectral optical depths over the Bay of Bengal, Arabian Sea and Indian Ocean, Curr. Sci. India, 81, 1617-1625, 2001. 